\title{
BMJ School closures and influenza: systematic Open review of epidemiological studies
}

\author{
Charlotte Jackson, ${ }^{1,2}$ Emilia Vynnycky, ${ }^{2}$ Jeremy Hawker, ${ }^{3}$ Babatunde Olowokure, ${ }^{3}$ \\ Punam Mangtani ${ }^{1}$
}

To cite: Jackson C,

Vynnycky E, Hawker J, et al. School closures and influenza: systematic review of epidemiological studies. BMJ Open 2013;3:e002149. doi:10.1136/bmjopen-2012002149

- Prepublication history and additional material for this paper are available online. To view these files please visit the journal online (http://dx.doi.org/10.1136/ bmjopen-2012-002149).

Received 12 October 2012 Revised 23 January 2013 Accepted 24 January 2013

This final article is available for use under the terms of the Creative Commons Attribution Non-Commercial 2.0 Licence; see http://bmjopen.bmj.com

\footnotetext{
${ }^{1}$ Department of Infectious Disease Epidemiology, London School of Hygiene and Tropical Medicine, London, UK

${ }^{2}$ Health Protection Agency, London, UK

${ }^{3}$ Health Protection Agency, Birmingham, UK
}

Correspondence to Dr Charlotte Jackson; charlotte.jackson@|shtm.ac.uk

\section{ABSTRACT}

Objective: To review the effects of school closures on pandemic and seasonal influenza outbreaks.

Design: Systematic review.

Data sources: MEDLINE and EMBASE, reference lists of identified articles, hand searches of key journals and additional papers from the authors' collections.

Study selection: Studies were included if they reported on a seasonal or pandemic influenza outbreak coinciding with a planned or unplanned school closure.

Results: Of 2579 papers identified through MEDLINE and EMBASE, 65 were eligible for inclusion in the review along with 14 identified from other sources. Influenza incidence frequently declined after school closure. The effect was sometimes reversed when schools reopened, supporting a causal role for school closure in reducing incidence. Any benefits associated with school closure appeared to be greatest among school-aged children. However, as schools often closed late in the outbreak or other interventions were used concurrently, it was sometimes unclear how much school closure contributed to the reductions in incidence.

Conclusions: School closures appear to have the potential to reduce influenza transmission, but the heterogeneity in the data available means that the optimum strategy (eg, the ideal length and timing of closure) remains unclear.

\section{INTRODUCTION}

During the 2009 influenza pandemic, schools were closed in many settings in efforts to reduce transmission. The WHO does not specifically recommend or discourage school closures during an influenza pandemic, as their potential benefits and harms may be context-specific, ${ }^{1}$ but has suggested that they be considered as part of a mitigation strategy. ${ }^{2}$ Their effects on transmission, however, remain poorly understood. ${ }^{3} \quad 4$ Closures may be proactive (occurring before transmission is established in the school) or reactive (a response to a school-based outbreak), and may involve closure of whole school(s) or dismissal of individual classes. ${ }^{4}$

\section{ARTICLE SUMMARY}

\section{Article focus}

- This systematic review assesses the effects of school closures on the transmission of influenza, including data from the recent 2009 pandemic as well as from previous pandemics and seasonal outbreaks.

Key message

- The available data suggest that school closure can be a useful intervention during influenza outbreaks, with the greatest benefits occurring among school-aged children.

Strengths and limitations of this study

- We have reviewed an extensive body of the literature on the effects of school closure on the incidence and transmission of influenza.

- The optimum timing and duration of closure are unclear because studies often differed in several respects, or used other interventions in addition to school closure.

A review of the evidence available before the 2009 pandemic concluded that school closures may be beneficial, depending on characteristics including age-specific attack rates. $^{4}$ Here, we review epidemiological studies to assess the effects of school closures on transmission and incidence of seasonal and pandemic influenza, updating and extending previous reviews ${ }^{2} 4$ to include data from the 2009 pandemic.

\section{METHODS}

\section{Search strategy and selection criteria}

MEDLINE and EMBASE were searched in January 2012, without language restrictions, for relevant papers published by the end of 2011 (see online supplementary appendix for search strategy). Eurosurveillance (23 April 2009 to 15 December 2011), Morbidity and Mortality Weekly Report (24 April 2009 to 23 December 2011) and Emerging Infectious Diseases (April 2009 to December 2011) were hand-searched. Results were supplemented 
using the reference lists of the articles identified and papers from the reviewers' collections. An additional PubMed search (for the words 'influenza' and 'school') was used to identify relevant papers published during October-December 2011 but not yet listed in MEDLINE or EMBASE.

Studies were included if they described one or more influenza outbreaks during which schools were initially open and subsequently closed, with or without other interventions. If papers presented several measures of influenza activity, the most specific data were extracted (eg, data on laboratory-confirmed influenza were extracted in preference to all-cause school absenteeism). Studies using modelling techniques to assess how school closure affected transmission based on real epidemic curves were eligible; however, predictive modelling studies exploring how school closure might affect a hypothetical outbreak were excluded. English translations (where available) of the titles and abstracts of papers written in other languages were screened, but these papers were ineligible for inclusion. Studies of outbreaks which started during school closure were excluded.

Abstracts and full text were screened initially by one reviewer $(\mathrm{CJ})$ and by a second reviewer $(\mathrm{PM})$ if the first reviewer was in doubt as to the paper's eligibility. Box 1 summarises the information extracted (by CJ) from the studies. Wherever possible, epidemic curves were plotted by transcribing daily or weekly data from figures or tables.

\section{Data analysis}

We summarised the data graphically and descriptively. We plotted the peak and cumulative attack rates (and 95\% CIs, calculated using standard methods for calculating CIs for proportions) for each study that provided an appropriate denominator. We calculated the normalised peak (peak AR/median AR) for datasets with a median AR greater than zero, to adjust approximately for differences in case definitions (this approach has been used elsewhere to adjust for intercity differences in case fatality proportions ${ }^{5}$ ). These estimates were stratified by the

Box 1 Information extracted from eligible studies (where presented)

- Study design

- Study population/setting (including size of population)

- Nature of school closure (eg, school holiday, response to outbreak)

- Duration of closure and number of schools affected

- Timing of closure in relation to influenza circulation

- Outcome measure(s) examined (eg, clinical ILI, virologically confirmed influenza)

- Association between school closure and outcome

- Epidemic curve (transcribed from graphs or figures); used to derive peak, cumulative and median attack rates

- Normalised peak attack rate (=peak attack rate/median attack rate) timing of closure, that is, whether schools closed before, coincident with or after the peak.

\section{RESULTS}

Of 2579 papers identified through MEDLINE and EMBASE, 430 were reviewed in full. Sixty-five of these studies were included in the review, along with 14 additional papers (figure 1; the supplementary PubMed search yielded no further eligible articles). Seventy-nine papers were thus included: 22 for seasonal and 57 for pandemic influenza (49, 1 and 7 from the 2009, 1968 and 1918 pandemics, respectively). Details of the studies are given in table 1 and see online supplementary tables S1 and S2.

\section{Description of the epidemics}

Nineteen and 41 epidemic curves were available on seasonal and pandemic influenza, respectively, (see online supplementary figures S1 and S2). School closure was often followed by a reduction in incidence, in children specifically or the general population. However, closure often occurred late in the outbreaks (table 1), and it is unclear whether it influenced the decline.

The cumulative and peak ARs varied widely for seasonal and pandemic influenza (figure 2). Normalised peaks partly account for differences in case definitions between studies, but also varied considerably (figure 3). There was no clear pattern in the cumulative, peak or normalised peak ARs plotted by timing of closure in relation to the peak. Relatively few schools closed before the peak (figures 2 and 3); of those that did, two also reopened before the peak. ${ }^{6} 7$ However, the early introduction of non-pharmaceutical interventions (NPIs), often including school closures, in US cities during the 1918 pandemic has been found to be associated with reductions in mortality. ${ }^{5} 89$ In Connecticut in 1918, three cities which closed schools experienced higher death rates than two which did not. ${ }^{10}$

\section{Age-specific effects of school closure}

The available age-specific data suggested that any benefits associated with school closure were greatest among school-aged children. ${ }^{11-25}$ During the 2009 pandemic in New Zealand, the age-standardised proportion of confirmed cases in 5-year-olds to 19-year-olds fell during the winter holiday and increased when schools reopened ${ }^{19}$; a slight increase in influenza-like illness (ILI) consultation rates when schools reopened was confined to 5-year-olds to 14-year-olds. ${ }^{14}$ Similar relationships between school closure and the ratio of the number of H1N1 infections in 5-year-olds to 20-year-olds to that in other age groups were reported for Mexico $^{23}$ and Peru. ${ }^{24}$ During the $1967-1968$ influenza season in Great Britain, general practitioner (GP) consultation rates for ILI among 5-year-olds to 14-year-olds declined during the winter holiday and increased when schools reopened; this effect was less clear in other age groups. ${ }^{17}$ 


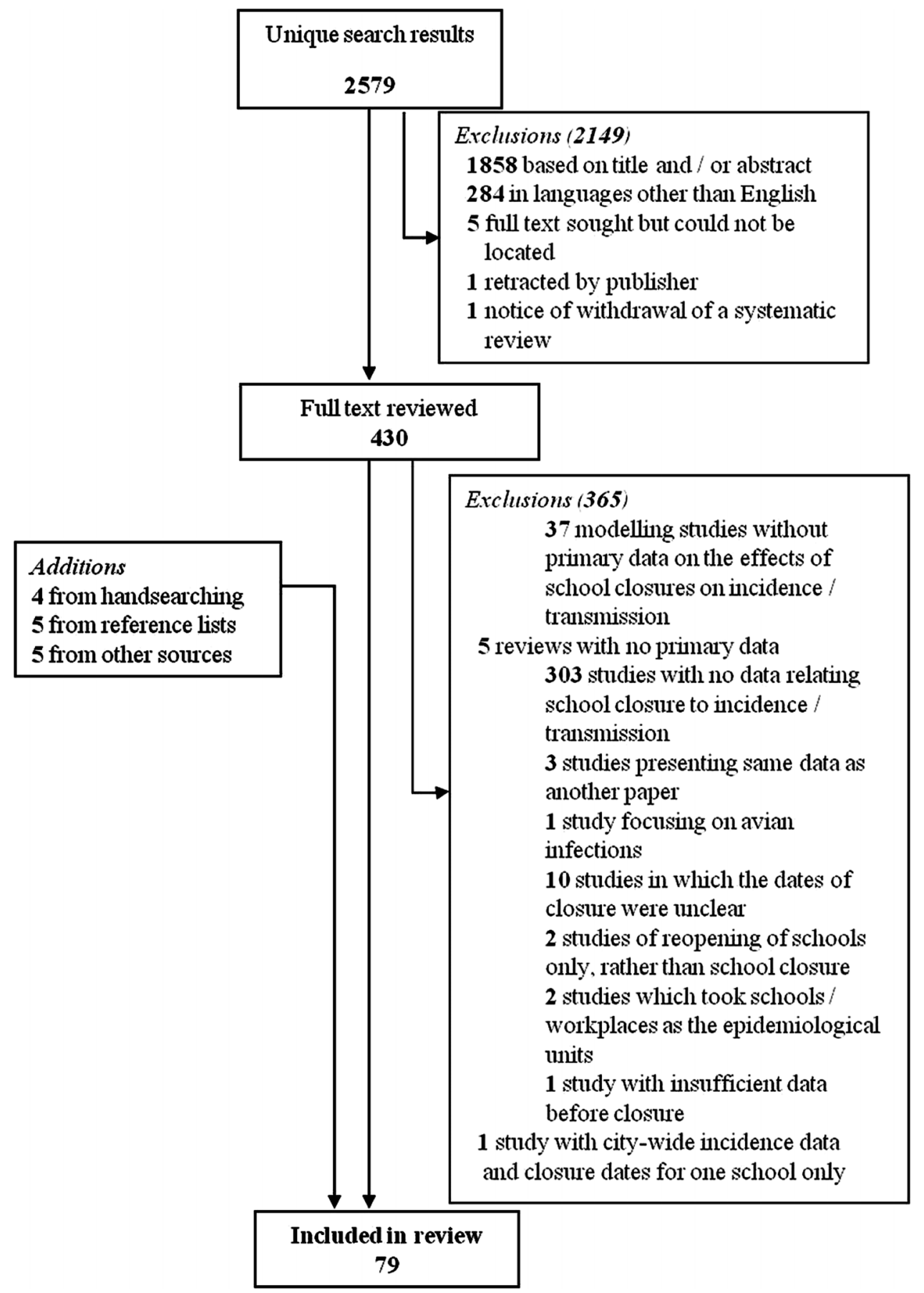

Figure 1 Identification of epidemiological studies of the effects of school closure on influenza outbreaks.

Winter holidays in Israel were associated with a reduction in the ratio between the number of clinic visits for influenza and those for non-respiratory complaints, in 6-year-olds to 12-year-olds, in three of five seasonal influenza periods studied. ${ }^{15}$ In one season, this ratio was also reduced in adults, and in another it was reduced for adults not living with 6-year-olds to 12-year-olds. When a 2-week teachers' strike coincided with an influenza outbreak in January 2000, closing $80 \%$ of elementary schools nationwide, this ratio decreased by $15 \%$ for 6-year-olds to 12 -year-olds ( $95 \%$ CI $6 \%$ to $23 \%$ ), but not for older individuals. As the authors note, children comprise a high proportion (34\%) of the Israeli population, which may contribute to any apparent benefit of closing schools in Israel. ${ }^{26}$

Similar data from four influenza seasons in Arizona are less consistent, partly because school closure rarely coincided with elevated influenza activity. ${ }^{18}$ During all four seasons, rates of laboratory-confirmed influenza in school-aged children were similar during the 2-week winter holiday and the preceding 2 weeks. In two seasons, this rate increased in the 2 weeks after schools reopened; in one other season, it was significantly lower on reopening than during closure. ${ }^{18}$ In comparison, 
Table 1 Features of the studies identified

\begin{tabular}{|c|c|}
\hline & $\begin{array}{l}\text { Number of } \\
\text { studies }\end{array}$ \\
\hline Total studies & 79 \\
\hline \multicolumn{2}{|l|}{ Type of outbreak } \\
\hline Seasonal & 22 \\
\hline 1918 pandemic & 7 \\
\hline 1968 pandemic & 1 \\
\hline 2009 pandemic & 49 \\
\hline \multicolumn{2}{|l|}{ Setting } \\
\hline Europe & 22 \\
\hline North America & 22 \\
\hline Central America & 5 \\
\hline South America & 3 \\
\hline Asia & 20 \\
\hline Africa & 1 \\
\hline Australasia & 6 \\
\hline \multicolumn{2}{|l|}{ Data provided on* } \\
\hline Children only & 25 \\
\hline General population & 29 \\
\hline School pupils and staff & 5 \\
\hline $\begin{array}{l}\text { Children and other specified groups } \\
\text { separately }\end{array}$ & 22 \\
\hline \multicolumn{2}{|l|}{ Reason for closure } \\
\hline High student absenteeism & 3 \\
\hline High staff absenteeism & 1 \\
\hline High student and staff absenteeism & 1 \\
\hline Other reactive closuret & 31 \\
\hline Proactive & 7 \\
\hline Planned holiday & 38 \\
\hline Other & 3 \\
\hline Unclear & 3 \\
\hline \multicolumn{2}{|l|}{ Period of closure } \\
\hline Continuous & 67 \\
\hline Intermittent & 8 \\
\hline Variable§ & 3 \\
\hline Not stated & 1 \\
\hline \multicolumn{2}{|l|}{ Other interventions in place } \\
\hline None & 20 \\
\hline Antivirals & 33 \\
\hline Other social distancing & 24 \\
\hline Vaccination & 8 \\
\hline Other & 20 \\
\hline \multicolumn{2}{|l|}{ Timing of closure } \\
\hline Before peak & 21 \\
\hline Same day/week as peak & 9 \\
\hline After peak & 36 \\
\hline Variable§ & 8 \\
\hline Unclear & 8 \\
\hline \multicolumn{2}{|l|}{ Duration of closure ${ }^{\star \star}$} \\
\hline$<7$ days & 8 \\
\hline $7-13$ days & 33 \\
\hline $14-20$ days & 19 \\
\hline$\geq 21$ days & 17 \\
\hline Variable§ & 6 \\
\hline Not stated & 2 \\
\hline
\end{tabular}

Studies may present more than one dataset and so appear in more than one row of each section.

*Each study may present more than one data source.

tClosure in response to outbreak, not stated as being for operational reasons.

$\ddagger$ Teachers' strike (2 studies) or response to SARS outbreak (1 study). $\S$ Studies of multiple US cities during the 1918 pandemic or multiple countries in 2009.

IDescribed in the included paper or related papers; excludes normal levels of vaccine and antiviral usage in seasonal datasets.

**Each study may present more than one dataset for which the durations of closure differed. rates in adults and preschool-aged children increased successively (though not always significantly) across the three 2-week periods in three of the seasons. ${ }^{18}$

Three studies which fitted transmission models to surveillance data also concluded that school closures mainly benefit children. ${ }^{12}{ }^{13}$ Analyses of French seasonal ILI data ${ }^{13}$ and ILI data from London during the 2009 pandemic ${ }^{22}$ estimated that school holidays did not affect adults' contact patterns; similarly, reductions in transmission following school closures in Hong Kong in 2009 occurred primarily among children. ${ }^{12}$

However, two studies of the 2009 pandemic suggested that school closure affected incidence in adults. One of these studies estimated the age-specific number of ILI cases due to pandemic H1N1 in England; estimated case numbers in most age groups decreased during the summer holiday and increased when schools reopened. $^{25}$ In Vojvodina, Serbia, incidence decreased among 5-year-olds to 14-year-olds and 15-year-olds to 64 -year-olds during a 1-week school closure. ${ }^{27}$

\section{Reversibility of effects}

Incidence sometimes rebounded when schools reopened, suggesting that school closure contributed to reducing incidence in some settings. For example, during the 2009 pandemic in England, the estimated weekly number of infections declined during the school summer holiday; a second wave occurred when schools reopened (see online supplementary figure S2). ${ }^{22}{ }^{28}$ Similar reversibility appeared in ILI consultation rates in Vojvodina in 2009. ${ }^{27}$ Datasets from the 2009 pandemic in Mexico ${ }^{23} 2930$ also suggested an increase in incidence after schools reopened (see online supplementary figure S2). Analyses of NPIs (usually including school closures) during the 1918 pandemic found that, in the cities studied, second waves occurred only after NPIs were lifted. ${ }^{58}$

In the Israeli data regarding seasonal influenza and the teachers' strike, the number of physician visits for acute respiratory illness was $42 \%$ lower during closure compared with the previous 2 weeks; incidence increased after the strike. ${ }^{26}$ During the 1999-2000 influenza season in Japan, the increase in incidence appeared to slow during the 2-week winter holiday and accelerated when schools reopened. ${ }^{7}$ Similarly, in Beijing in 2009, the cumulative incidence of laboratory-confirmed H1N1 influenza increased more markedly before and after a national school holiday than during the break. ${ }^{31}$

\section{Changes in transmission patterns from modelling analyses of epidemic data}

Several studies have fitted transmission models to observed epidemic data to estimate the reduction in contact rates associated with school closure. School holidays were estimated to reduce transmission of seasonal influenza among children by a median of $24 \%$ (range 20-29\%), based on rates of ILI in France from 1985 to 2006 , corresponding to a $16-18 \%$ reduction in total case numbers. ${ }^{13}$ During the 2009 pandemic in London, 

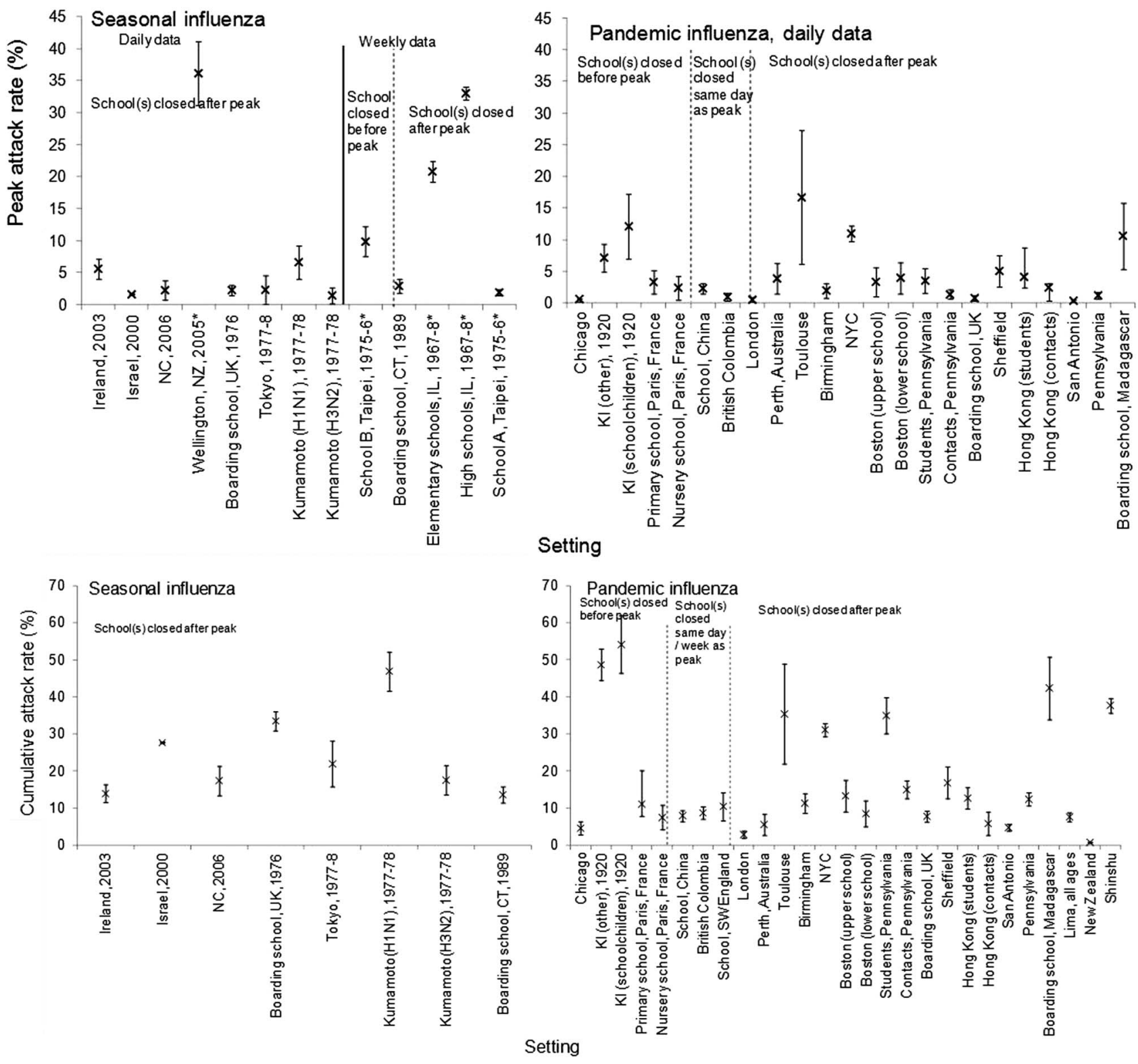

Figure 2 Peak cumulative attack rates recorded in the identified studies. Case definitions varied between studies (see online supplementary appendix); only studies which included a denominator are shown. Studies which reported peak prevalence of absenteeism are denoted by an asterisk. See online supplementary appendix for full details of datasets. All pandemic data are from 2009 except for Kelleys Island. BC, British Columbia; CT, Connecticut; IL, Illinois; KI, Kelleys Island; NC, North Carolina.

contact among 5-year-olds to 14-year-olds was reduced by an estimated $72 \%$ during the 6 -week summer holiday; the corresponding reduction during the 1-week halfterm holidays was $48 \% .^{22}$ In US cities in 1918 , changes in mortality were attributed to a combination of formal interventions (including school closure) and spontaneous social distancing. ${ }^{8}$ In Sydney in 1918, formal and spontaneous social distancing together were estimated to have reduced contact rates by up to $38 \% .^{32}$ Based on the influenza incidence data from the 2009 pandemic in Mexico City, school closure together with other interventions appeared to reduce the population contact rate by $23 \% .^{30}$ A subsequent analysis of national data from
Mexico estimated that the contact rate was reduced by $30 \%$ during the intervention period. ${ }^{23}$

In Hong Kong (also during the 2009 pandemic), closing primary schools, kindergartens and childcare centres proactively, together with the affected secondary schools, were estimated to reduce transmission by $70 \%$ among children and $25 \%$ in the population overall. ${ }^{12}$ The same study estimated the effective reproduction number $\left(R_{n}\right.$, the average number of secondary infectious persons generated by a single infectious person in a given population) as 1.7 before school closure, 1.5 during school closure and 1.1 during the subsequent school holidays. ${ }^{12}$ Daily estimates of $R_{n}$ in Hong Kong in 


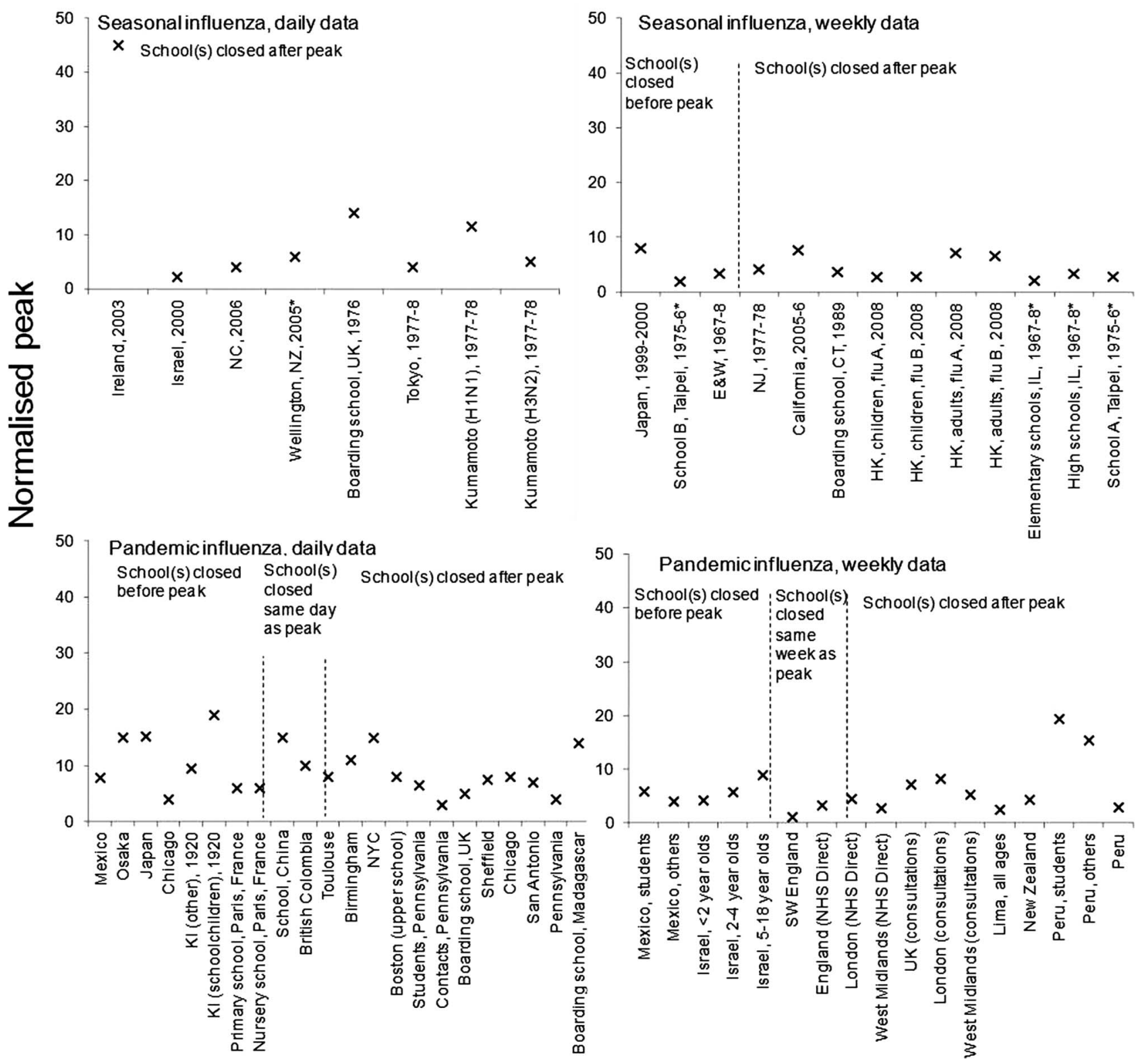

Figure 3 Normalised peak attack rates (estimated as peak attack rate/median attack rate) recorded in the identified studies; one study with an estimate normalised peak of 128 is excluded for clarity. ${ }^{82}$ Case definitions varied between studies (see online supplementary appendix). Studies which reported peak prevalence of absenteeism are denoted by an asterisk. HK, Hong Kong; IL, Illinois; KI, Kelleys Island; NC, North Carolina; SARI, severe acute respiratory infection.

2009 (based on a longer time series) also suggested a decline during school closure and a slight increase following reopening. ${ }^{33}$

Modelling techniques have also been used to estimate daily values of $R_{n}$ during a seasonal influenza outbreak in Hong Kong ${ }^{34}$ and the 2009 pandemic in Mexico City $^{23} 30$ and New Zealand. ${ }^{19}$ The Hong Kong analysis for seasonal influenza suggested that $R_{n}$ was not substantially affected by school closure, perhaps because closure occurred late in the outbreak when $R_{n}$ was already below one ${ }^{34}$ In Mexico City ${ }^{30}$ and New Zealand, $R_{n}$ was declining before schools closed and continued to decrease during closure; in New Zealand, $\mathrm{R}_{\mathrm{n}}$ increased briefly but not substantially when schools reopened. ${ }^{19}$
Analysis of a further outbreak in the USA detected no clear effect of school closure on transmission, which was attributed to the late timing of closure. ${ }^{20}$

Modelling analyses of the spatiotemporal spread of pandemic H1N1 in Europe in 2009 were able to reproduce observed incidence patterns only when contact rates were allowed to change specifically during each country's school holidays (holidays were assumed to eliminate transmission in schools and increase community transmission by a factor of 1.4) ${ }^{35}$ In all countries, holidays were estimated to delay the peak compared with a hypothetical situation without school closure. In contrast, regression analysis of estimates of $R_{n}$ in 12 European countries found no evidence of an effect of 
school holidays on transmission in the nine countries in which school holidays coincided with the study period. ${ }^{36}$ The authors proposed that this apparent lack of effect might result from changes in reporting, stochastic effects early in the outbreaks, and the fact that in some countries (including England) school holidays occurred outside the study period.

\section{Different school closure strategies}

In some outbreaks, individual schools were closed; in others, school closure was more widespread (see online supplementary tables S1 and S2). The effects of these different strategies could not be compared, due to both late implementation and differences between the studies in other factors (such as the duration of closure).

Analyses of the 1918 pandemic in US cities found that the duration of NPIs was negatively associated with the total excess death rate. ${ }^{9}$ In the datasets reviewed here, closures longer than 2 weeks were associated with reduced incidence or transmission in several studies of seasonal $^{37}$ and pandemic ${ }^{12} 28$ influenza, but not in others. $^{11} 38$ Two studies which suggested reasonably strong evidence of an effect of school closure (from France and Israel) reported on closures lasting 2 weeks. ${ }^{13}{ }^{26}$ Studies in Japan ${ }^{7}$ and England and Wales ${ }^{17}$ also suggested possible effects of 2-week closures on seasonal influenza. However, 2-week closures did not always appear to reduce transmission. ${ }^{34}$ Shorter closures, for example, of 1-2 weeks, may sometimes have contributed to reductions in transmission, ${ }^{22} 28303139$ but often had no obvious effect. ${ }^{40-43}$ In London, contacts between children were reduced more dramatically during a 6-week holiday than during 1-week breaks, but this may reflect different behaviour during the different holidays. ${ }^{22}$

\section{Use of multiple interventions}

In most of the pandemic influenza studies, other interventions were implemented alongside school closure and may have contributed to any reduction in incidence. In 2009, antiviral treatment and/or prophylaxis was commonly used in the studies identified. ${ }^{12} 14192038394144-56$ Public places were sometimes closed and/or large gatherings were discouraged or restricted. ${ }^{1629} 3057$ Some datasets from the 2009 pandemic included vaccination against the pandemic strain, although this was usually only available late in the study period, so it would not affect the included incidence data. ${ }^{28} 315658$ In 1918, school closures were often combined with other social distancing measures; 58932 the only study included from the 1968 pandemic was a vaccine trial. ${ }^{59}$ Of the few pandemic studies which mentioned no additional interventions, one suggested an effect of school closures: in Israel in 2009, three waves of infection corresponded to the planned closure and reopening of schools. ${ }^{60}$ In the England and Wales data for the 2009 pandemic, other interventions (vaccination and antivirals) were used to only a limited extent; incidence still clearly declined during the school summer holiday and increased afterwards. $^{28}$

Some studies of seasonal influenza mentioned additional interventions (eg, vaccination, ${ }^{61-63}$ prophylactic amantadine, ${ }^{64}$ hygiene promotion, ${ }^{37} 40 \quad 65$ closure of public places $^{37}$ and advice to avoid large gatherings ${ }^{43}$ ). However, some studies without additional interventions showed reductions in incidence and/or transmission during school closure. ${ }^{1326}$

\section{DISCUSSION}

This systematic review of the effects of school closures on influenza outbreaks extends previous reviews ${ }^{2} 4$ to include published experiences from the 2009 pandemic. The results suggest that school closure can reduce transmission of pandemic ${ }^{12}$ and seasonal ${ }^{1326}$ influenza among schoolchildren. Many datasets, however, show no clear effect of school closure. As noted by some authors, 204243 this may sometimes have been because schools shut late in the outbreak (often close to or after the peak).

In some studies, incidence increased when schools reopened. ${ }^{5} 781422262830$ This apparent reversibility provides evidence that school closure can cause reductions in influenza incidence. In two of the studies of seasonal influenza which showed reversibility, ${ }^{7}{ }^{26}$ no additional interventions (beyond usual seasonal interventions) were used. In many other datasets, multiple interventions were used, so the specific effects of school closures are difficult to isolate.

In 2009, several countries closed schools while in others, planned holidays coincided with outbreaks. Several datasets from this pandemic strengthen support for school closure as an intervention; however, others illustrate that benefits are not guaranteed and that timely closure may be challenging. The sensitivity of the 2009 pandemic to school closures probably reflects the high attack rates in children compared with adults; outbreaks in which children are less affected might be less sensitive to school closure.

Studies presenting age-stratified data suggested that the effects of school closure on transmission were greater among children than adults. Few studies stratified children further, for example, into primary and secondary school students. Older children might socialise more than younger children during school closures, so closing primary schools may have a greater effect on transmission than closing secondary schools (eg, in Hong Kong in 2009, primary schools were closed proactively while secondary schools closed if cases occurred among their students ${ }^{12}$ ).

The long-term effects of closing schools are unclear, as relatively few studies presented substantial data after schools reopened. For example, school closure could result in multiple peaks, potentially involving more cases than would otherwise have occurred. ${ }^{8}$ However, a study published since this review was conducted estimated that case numbers in Alberta, Canada, could have been up 
to twice as high as those seen if schools had not closed for planned holidays. ${ }^{66}$ It is difficult to compare reactive versus proactive closures, different durations of closure and local versus national closures as studies typically differed in several respects.

Some studies have concluded that reopening schools after holiday periods can accelerate epidemic growth (eg during the $1957^{6768}$ and $2009^{69}$ pandemics). These studies were beyond the scope of this review of the effects of closing schools during outbreaks, but they suggest that extending school holidays might delay the spread of an epidemic beginning during a break.

Results from analyses of seasonal influenza may not be directly applicable to a pandemic. Schools were often closed for planned holidays rather than in response to the outbreaks; contact patterns may differ between reactive school closures ${ }^{70}$ and holidays. ${ }^{71}$ Extrapolating from previous pandemics may also be problematic. Modelling studies ${ }^{72-74}$ have predicted that school closures will have the greatest effects if transmission occurs mainly among children. The importance of children in transmission has varied between pandemics; ${ }^{75}$ in 2009, attack rates were higher in children than in adults, probably because of pre-existing immunity in older individuals. ${ }^{76}$ Viral virulence will also influence individuals' responses to school closure and other interventions, for example, spontaneous social distancing during a mild pandemic may be less dramatic than occurred in 1918. Changes in household size, contact patterns, children's behaviour and school systems since 1918, 1957 and 1968 may also limit the generalisability of experiences from these pandemics. As noted in a study of the 1918 pandemic in Connecticut, reverse causality may occur when comparing rates in cities which closed schools to those in cities which did not, if closure was a response to a particularly severe local outbreak. ${ }^{10}$

One limitation of the datasets is that ascertainment may have changed during the outbreaks, due to changes in surveillance and care-seeking behaviour. Increases in ascertainment during an outbreak could obscure any reductions in incidence during school closures (eg in one study, enhanced surveillance began the day the school $\left.\operatorname{closed}^{55}\right)$. Conversely, the proportion of patients who undergo virological testing may be reduced late in an outbreak, and in some settings (eg New Zealand ${ }^{14}$ ) patients with ILI were discouraged from consulting GPs during the 2009 pandemic. The estimated proportion of influenza cases that were reported in Hong Kong declined to $\sim 5 \%$ of its original value during the move from containment to mitigation during the 2009 pandemic. ${ }^{12}$ In England, the introduction of the National Pandemic Flu Service telephone helpline coincided with the school holiday, and was estimated to have reduced the probability of GP consultation for adults with ILI from $16 \%$ to $1.8 \% .^{22}$

Case definitions may not always have been well suited to detecting any effect of school closure. For example, school absenteeism is a relatively non-specific measure, while laboratory specimens frequently represent severe infections (eg in the elderly, who may have little contact with children and therefore be relatively unaffected by school closure).

Influenza transmission is influenced by factors besides contact in schools, including temperature and absolute humidity (AH) ${ }^{77-80}$ Two studies which assessed the role of AH during the 2009 pandemic did not find strong evidence that it affected transmission. ${ }^{24} 36$ The two waves seen in the UK in 2009 could be explained by changes in contact patterns during school holidays. ${ }^{28} 81$ In a modelling study of data from Alberta, Canada, the bestfitting model included effects of temperature and school holidays on transmission, and predicted that if schools had not closed, the outbreak would have been restricted by temperature effects but would still have been 2.1 times larger than was observed in the province as a whole (1.38 and 1.54 times in the cities of Calgary and Edmonton, respectively). ${ }^{66} \mathrm{~A}$ study of the interplay between school calendars, $\mathrm{AH}$ and population susceptibility in enhancing influenza transmission concluded that high AH may prevent influenza outbreaks. ${ }^{78}$ However, if a sufficiently high proportion of the population is susceptible, outbreaks can occur even when $\mathrm{AH}$ is high; the opening of schools may enhance transmission. ${ }^{78}$ Taken together, these studies suggest that contact in schools is not the only determinant of influenza transmission, but it is one influential (and modifiable) factor.

Previous studies have estimated the effects of public-health interventions using transmission models. $^{8} 122030$ The development of such models is complicated for the datasets reviewed here, and would not necessarily have provided conclusive insight into the impact of school closures. For example, many factors are unknown and would need to be estimated or assumed for each dataset, such as the basic reproduction number, proportion of infections that were reported, effect of other interventions and the proportion of individuals who were immune at the start of the outbreak.

The review was limited to published studies, which could potentially introduce publication bias. However, many of the studies identified did not aim to evaluate the effects of school closure on transmission, so publication bias appears unlikely. This is supported by the apparent lack of an effect of school closure in many of the studies (including some of those which did specifically assess school closure as an intervention). A further limitation is that most papers were screened (and all data were extracted) by a single reviewer. Foreign language papers were excluded, but in most cases it was clear from the title and/or abstract (available in English) that the papers were not relevant to this review.

\section{CONCLUSIONS}

The available data suggest that school closures can potentially reduce transmission during an influenza outbreak, even in the absence of other interventions, 
although the optimal school closure strategy is unclear. The effect of school closures is larger for school-aged children than for other age groups, although there is some evidence that incidence in adults might also be reduced. During a future pandemic (or seasonal outbreaks during which schools are closed), it will be important to collect incidence data using systematic ascertainment and a consistent case definition, before, during and after school closure, to assess the effects of school closures on transmission. Analysis of comparable data from multiple outbreaks may help to overcome some of the problems with comparability and ascertainment discussed above, and clarifies which features determine the effectiveness of school closures. Although timely school closures may reduce transmission, other implications of school closure (eg, ethical and economic considerations $)^{4}$ and viral properties such as virulence must also be considered in policy decisions, and may depend on the local context. ${ }^{1}$

Acknowledgements This paper was developed from a review commissioned by the UK Health Protection Agency as part of its pandemic influenza programme. We thank Nadia Inglis, Angus Nicoll and two anonymous members of the HPA's Influenza and Respiratory Virus Programme Board for helpful comments on the review. We also thank the staff at the LSHTM library for assistance in locating papers.

Contributors $\mathrm{BO}$ and $\mathrm{JH}$ initiated the study and defined the initial research question. JH wrote the generic investigation plan and PM, CJ and EV developed the detailed methodology. CJ carried out the literature review and PM assessed any doubtful papers. CJ, PM and EV analysed the data. JH and $\mathrm{BO}$ contributed to interpretation of data. CJ, PM and EV drafted the manuscript, which was critically revised by $\mathrm{JH}$ and $\mathrm{BO}$. All authors approved the final version for publication.

Funding This work was partially funded by the Health Protection Agency; CJ was supported by a Research Training Fellowship from the National Institute for Health Research.

Competing interests None.

Provenance and peer review Not commissioned; externally peer reviewed.

Data sharing statement No additional data are available.

\section{REFERENCES}

1. World Health Organization. Reducing transmission of pandemic (H1N1) 2009 in school settings. A framework for national and local planning and response, 2009.

2. Bell DM, World Health Organization Writing Group. Non-pharmaceutica interventions for pandemic influenza, national and community measures. Emerg Infect Dis 2006;12:88-94.

3. Aledort JE, Lurie N, Wasserman J, et al. Non-pharmaceutical public health interventions for pandemic influenza: an evaluation of the evidence base. BMC Public Health 2007;7:208.

4. Cauchemez S, Ferguson NM, Wachtel C, et al. Closure of schools during an influenza pandemic. Lancet Infect Dis 2009;9:473-81.

5. Hatchett RJ, Mecher CE, Lipsitch M. Public health interventions and epidemic intensity during the 1918 influenza pandemic. Proc Natl Acad Sci USA 2007;104:7582-7.

6. Olson JG. School absenteeism during an outbreak of B/Hong Kong/ 5/72-like influenze virus in Taipei, Taiwan. Southeast Asian J Trop Med Public Health 1980;11:429-34.

7. Fujii $\mathrm{H}$, Takahashi $\mathrm{H}$, Ohyama $\mathrm{T}$, et al. Evaluation of the school health surveillance system for influenza, Tokyo, 1999-2000. Jpn J Infect Dis 2002;55:97-8.

8. Bootsma MC, Ferguson NM. The effect of public health measures on the 1918 influenza pandemic in U.S. cities. Proc Natl Acad Sci USA 2007;104:7588-93.
9. Markel H, Lipman HB, Navarro JA, et al. Non-pharmaceutical interventions implemented by US cities during the 1918-1919 influenza pandemic.[Erratum appears in JAMA. 2007 Nov 21;298 (19):2264]. JAMA 2007;298:644-54.

10. Winslow C-EA, Rogers JF. Statistics of the 1918 Epidemic of Influenza in Connecticut: with a consideration of the factors which influenced the prevalence of this disease in various communities. $J$ Infect Dis 1920;26:185-216.

11. Armstrong C, Hopkins R. An epidemiological study of the 1920 epidemic of influenza in an isolated rural community. Public Health Rep 1921;36:1671-702.

12. Wu JT, Cowling BJ, Lau EH, et al. School closure and mitigation of pandemic (H1N1) 2009, Hong Kong. Emerg Infect Dis 2010;16:538-41.

13. Cauchemez S, Valleron A-J, Boelle P-Y, et al. Estimating the impact of school closure on influenza transmission from Sentinel data. Nature 2008;452:750-4.

14. Baker MG, Wilson N, Huang QS, et al. Pandemic influenza $A(H 1 N 1)$ $\mathrm{v}$ in New Zealand: the experience from April to August 2009. Euro Surveill 2009;14:pii=19319.

15. Heymann AD, Hoch I, Valinsky L, et al. School closure may be effective in reducing transmission of respiratory viruses in the community. Epidemiol Infect 2009;137:1369-76.

16. Tinoco $\mathrm{Y}$, Razuri $\mathrm{H}$, Ortiz EJ, et al. Preliminary population-based epidemiological and clinical data on 2009 pandemic $\mathrm{H} 1 \mathrm{~N} 1$ influenza A ( $\mathrm{pH} 1 \mathrm{~N} 1)$ from Lima, Peru. Influenza Other Respir Viruses 2009;3:253-6.

17. Miller DL, Lee JA. Influenza in Britain 1967-68. J Hyg 1969;67:559-72.

18. Wheeler CC, Erhart LM, Jehn ML. Effect of school closure on the incidence of influenza among school-age children in Arizona. Public Health Rep 2010;125:851-9.

19. Paine S, Mercer GN, Kelly PM, et al. Transmissibility of 2009 pandemic influenza $A(\mathrm{H} 1 \mathrm{~N} 1)$ in New Zealand: effective reproduction number and influence of age, ethnicity and importations. Euro Surveill 2010;15:pii=19591.

20. Cauchemez S, Bhattarai A, Marchbanks TL, et al. Role of social networks in shaping disease transmission during a community outbreak of $2009 \mathrm{H} 1 \mathrm{~N} 1$ pandemic influenza. Proc Natl Acad Sci USA 2011;108:2825-30.

21. Marchbanks TL, Bhattarai A, Fagan RP, et al. An outbreak of 2009 pandemic influenza $A(\mathrm{H} 1 \mathrm{~N} 1)$ virus infection in an elementary schoo in Pennsylvania. Clin Infect Dis 2011;52(Suppl 1):S154-60.

22. Birrell PJ, Ketsetzis G, Gay NJ, et al. Bayesian modeling to unmask and predict influenza $\mathrm{A} / \mathrm{H} 1 \mathrm{~N} 1 \mathrm{pdm}$ dynamics in London. Proc Natl Acad Sci USA 2011;108:18238-43.

23. Chowell G, Echevarria-Zuno S, Viboud C, et al. Characterizing the epidemiology of the 2009 influenza A/H1N1 pandemic in Mexico. PLOS Med 2011;8:e1000436.

24. Chowell G, Viboud C, Munayco CV, et al. Spatial and temporal characteristics of the $2009 \mathrm{~A} / \mathrm{H} 1 \mathrm{~N} 1$ influenza pandemic in Peru. PLOS ONE 2011;6:e21287.

25. Evans $B$, Charlett $A$, Powers $C$, et al. Has estimation of numbers of cases of pandemic influenza H1N1 in England in 2009 provided a useful measure of the occurrence of disease? Influenza Other Respir Viruses 2011;5:e504-12.

26. Heymann A, Chodick G, Reichman B, et al. Influence of schoo closure on the incidence of viral respiratory diseases among children and on health care utilization. Pediatr Infect Dis $J$ 2004;23:675-7.

27. Petrovic V, Seguljev Z, Cosic G, et al. Overview of the winter wave of 2009 pandemic influenza $\mathrm{A}(\mathrm{H} 1 \mathrm{~N} 1) \mathrm{v}$ in Vojvodina, Serbia. Croat Med J 2011;52:141-50.

28. Baguelin $M$, Hoek AJV, Jit $M$, et al. Vaccination against pandemic influenza $\mathrm{A} / \mathrm{H} 1 \mathrm{~N} 1 \mathrm{v}$ in England: a real-time economic evaluation. Vaccine 2010;28:2370-84.

29. Echevarria-Zuno S, Mejia-Arangure JM, Mar-Obeso AJ, et al Infection and death from influenza A H1N1 virus in Mexico: a retrospective analysis. Lancet 2009;374(9707):2072-9.

30. Cruz-Pacheco G, Duran L, Esteva L, et al. Modelling of the influenza $A(H 1 N 1) v$ outbreak in Mexico City, April-May 2009, with control sanitary measures. Euro Surveill 2009;14:19254.

31. Wu J, Xu F, Lu L, et al. Safety and effectiveness of a $2009 \mathrm{H} 1 \mathrm{~N} 1$ vaccine in Beijing. N Engl J Med 2010;363:2416-23.

32. Caley P, Philp DJ, McCracken K. Quantifying social distancing arising from pandemic influenza. $J R$ Soc Interface 2008;5:631-9.

33. Cowling BJ, Lau MSY, Ho LM et al. The effective reproduction number of pandemic influenza: prospective estimation. Epidemiology 2010;21:842-46.

34. Cowling BJ, Lau EHY, Lam CLH, et al. Effects of school closures, 2008 winter influenza season, Hong Kong. Emerg Infect Dis 2008;14:1660-2. 
35. Merler S, Ajelli M, Pugliese A, et al. Determinants of the spatiotemporal dynamics of the $2009 \mathrm{H} 1 \mathrm{~N} 1$ pandemic in Europe: implications for real-time modelling. PLoS Comput Biol 2011;7: e1002205.

36. Flasche S, Hens N, Boëlle P-Y, et al. Different transmission patterns in the early stages of the influenza $\mathrm{A}(\mathrm{H} 1 \mathrm{~N} 1) \mathrm{v}$ pandemic: a comparative analysis of 12 European countries. Epidemics 2011;3:125-33.

37. Lo JY, Tsang TH, Leung YH, et al. Respiratory infections during SARS outbreak, Hong Kong, 2003. Emerg Infect Dis 2005;11:1738-41.

38. Gomez J, Munayco C, Arrasco J, et al. Pandemic influenza in a southern hemisphere setting: the experience in Peru from May to September, 2009. Euro Surveill 2009;14:pii=19371.

39. Kawaguchi R, Miyazono M, Noda T, et al. Influenza (H1N1) 2009 outbreak and school closure, Osaka Prefecture, Japan. Emerg Infect Dis 2009;15:1685.

40. Danis K, Fitzgerald M, Connell J, et al. Lessons from a pre-season influenza outbreak in a day school. Commun Dis Public Health 2004; 7:179-83.

41. Calatayud L, Kurkela S, Neave PE, et al. Pandemic (H1N1) 2009 virus outbreak in a school in London, April-May 2009: an observational study. Epidemiol Infect 2010; 138:183-91.

42. Rodriguez CV, Rietberg K, Baer A, et al. Association between school closure and subsequent absenteeism during a seasonal influenza epidemic. Epidemiology 2009;20:787-92.

43. Johnson AJ, Moore ZS, Edelson PJ, et al. Household responses to school closure resulting from outbreak of influenza B, North Carolina. Emerg Infect Dis 2008;14:1024-30.

44. Smith A, Coles S, Johnson S, et al. An outbreak of influenza A (H1N1)v in a boarding school in South East England, May-June 2009. Euro Surveill 2009;14:pii=19263.

45. Effler PV, Carcione D, Giele C, et al. Household responses to pandemic (H1N1) 2009-related school closures, Perth, Western Australia. Emerg Infect Dis 2010;16:205-11.

46. Health Protection Agency West Midlands H1N1v Investigation Team Preliminary descriptive epidemiology of a large school outbreak of influenza $\mathrm{A}(\mathrm{H} 1 \mathrm{~N} 1) \mathrm{v}$ in the West Midlands, United Kingdom, May 2009. Euro Surveill 2009;14:pii=19264.

47. Wallensten A, Oliver I, Lewis D, et al. Compliance and side effects of prophylactic oseltamivir treatment in a school in South West England. Euro Surveill 2009;14:pii=19285

48. Strong $\mathrm{M}$, Burrows J, Stedman $\mathrm{E}$, et al. Adverse drug effects following oseltamivir mass treatment and prophylaxis in a schoo outbreak of 2009 pandemic influenza $\mathrm{A}(\mathrm{H} 1 \mathrm{~N} 1)$ in June 2009 Sheffield, United Kingdom. Euro Surveill 2010;15:pii/19565.

49. Guinard A, Grout L, Durand C, et al. Outbreak of influenza A(H1N1) $v$ without travel history in a school in the Toulouse district, France, June 2009. Euro Surveill 2009;14:pii=19265.

50. France AM, Jackson M, Schrag S, et al. Household transmission of 2009 influenza A (H1N1) virus after a school-based outbreak in New York City, April-May 2009. J Infect Dis 2010;201:984-92.

51. Lessler J, Reich NG, Cummings DAT, et al. Outbreak of 2009 pandemic influenza $A(\mathrm{H} 1 \mathrm{~N} 1)$ at a New York City school. N Engl J Med 2009;361:2628-36.

52. Nishiura $\mathrm{H}$, Castillo-Chavez $\mathrm{C}$, Safan $\mathrm{M}$, et al. Transmission potential of the new influenza $A(\mathrm{H} 1 \mathrm{~N} 1)$ virus and its age-specificity in Japan. Euro Surveill 2009;14:pii=19227.

53. Shimada $\mathrm{T}, \mathrm{Gu} \mathrm{Y}, \mathrm{Kamiya} \mathrm{H}$, et al. Epidemiology of influenza $\mathrm{A}$ (H1N1)v virus infection in Japan, May-June 2009. Euro Surveill 2009;14(24):pii=19244.

54. Carrillo-Santisteve P, Renard-Dubois S, Cheron G, et al. 2009 pandemic influenza $\mathrm{A}(\mathrm{H} 1 \mathrm{~N} 1)$ outbreak in a complex of schools in Paris, France, June 2009. Euro Surveill 2010;15:pii=19599.

55. Huai Y, Lin J, Varma JK, et al. A primary school outbreak of pandemic 2009 influenza A (H1N1) in China. Influenza Other Respir Viruses 2010;4:259-66.

56. Poggensee G, Gilsdorf A, Buda S, et al. The first wave of pandemic influenza (H1N1) 2009 in Germany: from initiation to acceleration. BMC Infect Dis 2010;10:155.

57. Miller JC, Danon L, O'Hagan JJ, et al. Student behavior during a school closure caused by pandemic influenza A/H1N1. PLoS ONE 2010;5:e10425.
58. Hsueh P-R, Lee P-I, Hsiang Chiu A-W, et al. Pandemic (H1N1) 2009 vaccination and class suspensions after outbreaks, Taipei City, Taiwan. Emerg Infect Dis 2010;16:1309-11.

59. Monto AS, Davenport FM, Napier JA, et al. Modification of an outbreak of influenza in Tecumseh, Michigan by vaccination of schoolchildren. J Infect Dis 1970;122:328-32.

60. Engelhard D, Bromberg M, Averbuch D, et al. Increased extent of and risk factors for pandemic (H1N1) 2009 and seasonal influenza among children, Israel. Emerg Infect Dis 2011;17:1740-43.

61. Briscoe $\mathrm{JH}$. The protective effect of influenza vaccine in a mixed influenza A and B epidemic in a boys' boarding school. J R Coll Gen Pract 1977;27:28-31.

62. Farley TA, St. Germain JM, Chamberlain LA, et al. The impact of influenza vaccination on respiratory illness at a boarding school. J Am Coll Health 1992;41:127-31.

63. Sonoguchi T, Naito H, Hara M. Cross-subtype protection in humans during sequential, overlapping, and/or concurrent epidemics caused by $\mathrm{H} 3 \mathrm{~N} 2$ and $\mathrm{H} 1 \mathrm{~N} 1$ influenza viruses. $J$ Infect Dis 1985;151:81-8.

64. Davies JR, Grilli EA, Smith AJ, et al. Prophylactic use of amantadine in a boarding school outbreak of influenza A. J R Coll Gen Pract 1988;38:346-8

65. Cashman P, Massey $P$, Durrheim D, et al. Pneumonia cluster in a boarding school-implications for influenza control. Commun Dis Intell 2007;31:296-8.

66. Earn DJ, He D, Loeb MB, et al. Effects of school closure on incidence of pandemic influenza in Alberta, Canada. Ann Intern Med 2012;156:173-81.

67. Brunyate WDT, Fleming GM, Llopis A, et al. The early stages of the 1957 influenza epidemic in England and Wales in relation to the re-assembly of schools. Mon Bull Minist HIth Lab Serv 1961;20:88-92.

68. Dunn FL, Carey DE, Cohen A, et al. Epidemiologic studies of Asian influenza in a Louisiana parish. Am J Hyg 1959;70:351-71.

69. Chao DL, Halloran ME, Longini IM Jr. School opening dates predict pandemic influenza $A(\mathrm{H} 1 \mathrm{~N} 1)$ outbreaks in the United States. J Infect Dis 2010;202:877-80.

70. Jackson C, Mangtani P, Vynnycky E, et al. School closures and student contact patterns. Emerg Infect Dis 2011;17:245-47.

71. Eames KTD, Tilston NL, White PJ, et al. The impact of illness and the impact of school closure on social contact patterns. Health Technol Assess 2010;14:267-312.

72. Glass K, Barnes B. How much would closing schools reduce transmission during an influenza pandemic? Epidemiology 2007;18:623-8.

73. Vynnycky E, Edmunds WJ. Analyses of the 1957 (Asian) influenza pandemic in the United Kingdom and the impact of school closures. Epidemiol Infect 2008;136:166-79.

74. Milne GJ, Kelso JK, Kelly HA, et al. A small community model for the transmission of infectious diseases: comparison of school closure as an intervention in individual-based models of an influenza pandemic. PLOS ONE 2008;3:e4005.

75. Davis LE, Caldwell GG, Lynch RE. Hong Kong influenza: the epidemiologic features of a high school family study analyzed and compared with a similar study during the 1957Asian influenza epidemic. Am J Epidemiol 1970;92:520.

76. Miller E, Hoschler K, Hardelid P, et al. Incidence of 2009 pandemic influenza A H1N1 infection in England: a cross-sectional serological study. Lancet 2010;375:1100-8.

77. Lowen AC, Mubareka S, Steel J, et al. Influenza virus transmission is dependent on relative humidity and temperature. PLoS Pathog 2007;3:e151.

78. Shaman J, Goldstein E, Lipsitch M. Absolute humidity and pandemic versus epidemic influenza. Am J Epidemiol 2011;173:127-35.

79. Shaman J, Kohn M. Absolute humidity modulates influenza survival, transmission, and seasonality. Proc Natl Acad Sci USA 2009;106:3243-8.

80. Shaman J, Pitzer VE, Viboud C, et al. Absolute humidity and the seasonal onset of influenza in the continental United States. PLoS Biol 2010;8:e1000316.

81. Eames KT, Tilston NL, Brooks-Pollock E, et al. Measured dynamic social contact patterns explain the spread of H1N1v influenza. PLoS Comput Biol 2012;8:e1002425.

82. Uchida M, Tsukahara T, Kaneko M, et al. Swine-origin influenza A outbreak 2009 at Shinshu University, Japan. BMC Public Health 2011;11:79. 